\title{
PCR cuantitativa para la detección del virus de la tristeza de los cítricos en Colombia
}

\section{Quantitative PCR for detection of Citrus tristeza virus in Colombia}

Fecha de recepción: 8 de agosto de 2017

Fecha de aprobación: 23 de diciembre de 2017

Luis Miguel Solano-Luna ${ }^{1}$

Edisson Chavarro-Mesa²

Jorge Evelio Ángel-Díaz ${ }^{3}$

DOI: https://doi.org/10.19053/01228420.v15.n1.2018.7789

\section{Resumen}

Se aplicó la técnica de reacción en cadena de la polimerasa en tiempo real (qRT-PCR), usando SYBR Green para la detección específica del virus de la tristeza de los cítricos (CTV) en Colombia. Una pareja de iniciadores, diseñados a partir de secuencias conservadas en los marcos abiertos de lectura (ORF's) 1b y 2, permitió amplificar el ARN genómico (ARNg), y un producto de 186 pb fue obtenido sin la presencia de dímeros o inespecificidad. El análisis de la curva de fusión mostró un pico entre $81{ }^{\circ} \mathrm{C}$ y $83{ }^{\circ} \mathrm{C}$, con un coeficiente de correlación de 0,998 y una eficiencia de 99,1 \%. La curva estándar se desarrolló a partir de una amplificación del producto de 186 pb y permitió realizar un análisis cuantitativo de las muestras, con un rango de detección de $1 \times 10^{8}$ hasta $1 \times 10^{3}$ copias de RNAg y con valores de coeficiente de variación bajos. La acumulación de CTV fue más alta en tejido foliar y en frutos que en corteza; entretanto, las diferencias demostradas entre varias especies de cítricos susceptibles a la infección fueron mínimas. Los resultados de este trabajo muestran que la mayor concentración de virus se encontró en el tercio superior de las plantas analizadas, seguida por el tercio bajo y, por último, el tercio medio. La qRT-PCR es un método específico y sensible de interés práctico en los procesos de detección de las enfermedades virales presentes en el cultivo de los cítricos y otros cultivos de interés comercial.

Palabras clave: Closterovirus; cuantificación absoluta; detección de patógenos vegetales; enfermedades de los cítricos; PCR en tiempo real SYBR Green.

1 Esp. Centrales Eléctricas del Norte de Santander-CENS- (Cúcuta-Norte de Santander, Colombia). ORCID: 0000-00030215-8533.

2 Ph.D. Facultad de Ciencias Básicas, Universidad Tecnológica de Bolívar -UTB- (Cartagena-Bolívar, Colombia). echavarro@utb.edu.co. ORCID: 0000-0001-8031-5907.

3 Ph.D. Laboratorio Nacional de Diagnóstico Fitosanitario, Instituto Colombiano Agropecuário -ICA- (Bogotá-Distrito Capital, Colombia). jorge.angel@ica.gov.co. ORCID: 0000-0003-3179-8759. 


\begin{abstract}
Real-time quantitative PCR (qRT-PCR) was applied using SYBR Green for the specific detection of Citrus tristeza virus (CTV) in Colombian. Genomic RNA (gRNA) was amplified using primers designed from conserved sequences in the open reading frames (ORF's) $1 \mathrm{~b}$ and 2 . We obtained a 186 bp product with neither dimers nor non-specificity. The analysis of the melting curve showed a peak between $81{ }^{\circ} \mathrm{C}$ and $83^{\circ} \mathrm{C}$, with a correlation coefficient of 0.998 and an efficiency of $99.1 \%$. The amplification of the 186 bp fragment resulted in the standard curve, which allowed the quantitative analysis of the samples with a detection range between $1 \times 10^{8}$ and $1 \times 10^{3}$ genomic RNA copies, with low variation coefficients. CTV accumulation was higher in foliar and fruit tissue than in the bark, and the differences observed among several citrus species susceptible to infection were minimal. The highest concentration of virus was found in the upper third of the analyzed plants, followed by the lower third and finally the middle third. The qRT-PCR is a specific and sensitive method, with a practical interest for the detection of viral diseases in citrus plants and other crops of commercial interest.
\end{abstract}

Keywords: absolute quantification; citrus diseases; Closterovirus; detection of plant pathogens; real-Time PCR SYBR Green.

\title{
Para citar este artículo:
}

Solano-Luna LM., Chavarro-Mesa E., Ángel-Díaz JE. PCR cuantitativa para la detección del virus de la tristeza de los cítricos en Colombia. Ciencia y Agricultura. 2018; 15(1): 7-18. 


\section{Introducción}

La citricultura constituye el segundo renglón de importancia económica en el área de la producción de frutas en Colombia, pero enfrenta graves amenazas fitosanitarias debido a la presencia de enfermedades virales y a la alta incidencia de insectos vectores que contribuyen a su propagación $(1,2)$. El virus de la tristeza de los cítricos (CTV) es el agente causal de la enfermedad viral de mayor impacto económico en este cultivo $(3,4)$. El amplio espectro de los síntomas provocados por el CTV define la enfermedad como un síndrome, lo que se relaciona con la complejidad de la estructura poblacional de los aislamientos de campo y la existencia de varios genotipos virales distribuidos globalmente $(2,5,6)$. El CTV pertenece al género Closterovirus $(4,7,8)$; es una partícula flexuosa de $2000 \mathrm{~nm}$ de longitud por $11 \mathrm{~nm}$ de diámetro, que contiene una sola banda de ARN con sentido positivo, de un tamaño calculado de $20 \mathrm{~Kb}(4,9)$, organizado en 12 marcos abiertos de lectura (ORF's) $(4,8,10)$. El término Tristeza hace referencia al decaimiento foliar que el virus ocasiona en las muchas especies de cítricos que infecta y que han sido injertadas sobre patrones de naranjo agrio $(\mathrm{Ci}-$ trus aurantium) $(4,8,11)$. Durante muchos años, el diagnóstico de la infección por CTV fue realizado mediante técnicas como la observación de síntomas; estas pruebas biológicas se realizan a través de la inoculación, preferentemente por injerto de plantas indicadoras, como lima mexicana (Citrus aurantifolia); por métodos serológicos, basados en la reacción de determinantes antigénicos del virus con anticuerpos monoclonales y policlonales; por hibridación molecular con el ADN complementario o por transcripción reversa seguida de la reacción en cadena de la polimerasa (RT-PCR) $(12,13)$. Sin embargo, ninguno de estos métodos proporciona una cuantificación acertada de la acumulación del virus en tejidos infectados. La cuantificación de partículas virales es importante para diversos propósitos, incluyendo la asociación potencial de la intensidad del síntoma con la acumulación de variantes virales, la evaluación de la resistencia de las variedades de cítricos o de plantas transgénicas a diversos aislados del virus o la evaluación de los efectos de la carga viral sobre la transmisibilidad del vector (14-16).

La técnica de reacción en cadena de la polimerasa en tiempo real (qRT-PCR) ha sido ampliamente utilizada en estudios de la expresión de genes, detección de ácidos nucléicos específicos presentes en diversos tipos de muestras, así como en el diagnóstico y la cuantificación específica $(2,13,17-22)$. La prueba de transcripción reversa seguida de la pcr en tiempo real (qRT-PCR) presenta sensibilidad, especificidad y reproducibilidad, condiciones de interés práctico que justifican su uso para la detección del patógeno. Además, la posibilidad de obtener una cuantificación exacta del número de copias de ARN molde presente en una muestra hace de la qRT-PCR una herramienta valiosa para estudiar diversos aspectos de la biología del virus $(2,5,7,23)$. Los protocolos más usados por PCR en tiempo real utilizan dos diferentes métodos de detección: en el primero, el ADN sintetizado es detectado directamente mediante el fluorocromo SYBR Green, que se intercala entre las dos bandas de ADN, y en el segundo, el ADN hibrida con una sonda (sonda TaqMan ${ }^{\oplus}$ que lleva un fluoróforo ligado a su extremo $5^{\prime}$ y a un apagador (quencher) en su extremo 3'; la fluorescencia de la sonda hibridada es apagada debido a la proximidad de los dos fluoroforos, pero es detectada después de que la ADN polimerasa se desplaza e hidroliza la sonda $(19,24)$. La cantidad de moldes se determina por cuantificación absoluta o relativa; en la primera, el número real de moldes de ácidos nucléicos presente en una muestra es determinado con una curva estándar, construida por amplificación de cantidades conocidas de moldes; en la segunda, la cantidad relativa de ácidos nucléicos presentes en diversas muestras se observa en comparación con un control interno, pero no se proporciona ningún indicio del número real de copias presentes en cada muestra $(18-20,25)$.

El objetivo del presente trabajo fue aplicar un método de detección molecular del virus de la tristeza de los cítricos (CTV) en Colombia mediante la técnica de transcripción reversa seguida de la reacción en cadena de la polimerasa en tiempo real (qRT-PCR) en diferentes tejidos y partes de la plan- 
ta, con el fin de generar información para futuros trabajos sobre este y otros agentes fitopatógenos que pueden afectar el cultivo de los cítricos. Para esto se emplearon un par de iniciadores diseñados previamente por el IVIA (Instituto Valenciano de Investigación Agraria) (7).

Se implementó un protocolo de RT-PCR en tiempo real, usando SYBR Green, estableciéndose una curva estándar externa para la cuantificación absoluta que pudiera cuantificar el número real de moldes de ARNg en extractos totales de ARN de tejidos de cítricos infectados. Este procedimiento permitió cuantificar el virus CTV en especies de cítricos y en diferentes tejidos infectados con el patógeno, muestreados en cultivos citrícolas colombianos.

\section{Materiales y métodos}

\section{A. Recolección de muestras}

El tipo de muestreo fue por selección intencionada o muestreo de conveniencia; en este tipo de muestreo la "representatividad" la establece subjetivamente el investigador (26). El material biológico con síntomas de clorosis venosa, amarillamiento y decaimiento fue recolectado entre los meses de junio-julio, bajo una temperatura ambiental de $22{ }^{\circ} \mathrm{C}$ en promedio, en las zonas productoras de cítricos de los departamentos del Meta (Villavicencio, La Libertad-Corpoica), Norte de Santander (Bochalema), Casanare (Yopal) y Cundinamarca (Mosquera-Tibaitatá). Se obtuvieron un total de 19 muestras a partir de 6 plantas de cítricos, las cuales consistieron en tejido foliar, corteza y frutos de distintas plantas de cítricos, como se observa en la Tabla I.

Tabla I. Registro de muestras recolectadas a partir de plantas de cítricos con presencia de síntomas de CTV.

\begin{tabular}{|c|c|c|c|}
\hline Código & Tipo muestra & Planta de cítrico & Ubicación \\
\hline V01F & Tejido foliar & \multirow{3}{*}{ Limón Tahitía en Cleopatra } & \multirow{9}{*}{$\begin{array}{c}\text { Villavicencio } \\
4^{\circ} 9^{\prime} 0^{\prime \prime} \mathrm{N}, 73^{\circ} 38^{\prime} 0^{\prime \prime} \mathrm{W}\end{array}$} \\
\hline V01C & Corteza & & \\
\hline $\mathrm{V} 01 \mathrm{Fr}$ & Fruto & & \\
\hline V02F & Tejido foliar & \multirow{6}{*}{ Limón Tahití en Sunky x Jacobson } & \\
\hline V02C & Corteza & & \\
\hline $\mathrm{V} 02 \mathrm{Fr}$ & Fruto & & \\
\hline V03F & Tejido foliar & & \\
\hline V03C & Corteza & & \\
\hline $\mathrm{V} 03 \mathrm{Fr}$ & Fruto & & \\
\hline $\mathrm{C} 01$ & \multirow{2}{*}{ Tejido foliar* } & \multirow{2}{*}{ Naranjo dulce ${ }^{b}$} & Bochalema \\
\hline $\mathrm{C} 02$ & & & $7^{\circ} 37^{\prime} 0^{\prime \prime} \mathrm{N}, 72^{\circ} 39^{\prime} 0^{\prime \prime} \mathrm{W}$ \\
\hline Y01 & \multirow{2}{*}{ Tejido foliar* } & \multirow{2}{*}{ Naranjo dulce } & Yopal \\
\hline Y02 & & & $5^{\circ} 21^{\prime} 0^{\prime \prime} \mathrm{N}, 72^{\circ} 24^{\prime} 0^{\prime \prime} \mathrm{W}$ \\
\hline Ica $01 \mathrm{~F}$ & Tejido foliar & \multirow{3}{*}{ Naranjo dulce } & \multirow{6}{*}{$\begin{array}{c}\text { Mosquera } \\
4^{\circ} 35^{\prime} 53^{\prime \prime} \mathrm{N}, 74^{\circ} 4^{\prime} 33^{\prime \prime} \mathrm{W}\end{array}$} \\
\hline Ica 01C & Corteza & & \\
\hline Ica 01Fr & Fruto & & \\
\hline Ica $02 \mathrm{~F}$ & Tejido foliar & \multirow{3}{*}{ Limón mandarino $^{c}$} & \\
\hline Ica 02C & Corteza & & \\
\hline Ica $02 \mathrm{Fr}$ & Fruto & & \\
\hline
\end{tabular}

*Para las regiones de Bochalema y Yopal solo fue enviado tejido foliar. Nombres científicos para las especies de cítricos analizadas; a Citrus latifolia, b Citrus sinensis, c Híbrido: Citrus x limonia. 


\section{B. Extracción de ARN total}

La extracción se realizó a partir de 50-100 mg de tejido vegetal tratado con nitrógeno líquido, pulverizado en mortero estéril y utilizando el reactivo TRIZOL $^{\circledR}$ (Invitrogen ${ }^{\circledR}$ ), siguiendo las instrucciones del fabricante. Posteriormente, se analizó la calidad de la extracción, mediante cuantificación espectrofotométrica (relación de absorbancia, A260/A280), en un NanoDrop Spectrophotometer ND-1000 ${ }^{\circledR}$. En promedio se obtuvieron $165 \mathrm{ng} / \mu \mathrm{l}$ y una relación A260/A280 de 1.9 para las extracciones totales del ácido nucleico.

\section{Amplificación y clonación de un fragmento de ARN genómico (ARNg) del virus de la tristeza de los cítricos (CTV)}

El proceso de amplificación se llevó a cabo en dos etapas; la primera fue la transcripción reversa o la síntesis del ADN complementario (ADNc), utilizando el kit Super Script II First-Strand Synthesis System ${ }^{\circledR}$ for RT-PCR, Invitrogen ${ }^{\circledR}$. Posteriormente, se utilizó el ADNc obtenido para amplificar un fragmento a partir de regiones conservadas en los ORF's $1 b$ y 2 del virus, donde las condiciones de concentración final de reacción fueron: $0.2 \mu \mathrm{M}$ de cada iniciador (PM197F 5'-CGCCAATTTGATCTGTGAACG-3' y PM198R 5'-GCGAAAGCAAACATCTCGACTC-3'), 1X buffer de PCR, 2 mM de $\mathrm{MgCl} 2,0.2 \mathrm{mM}$ de dNTP's y 0.1 $\mathrm{U} / \mu$ l de Taq ADN polimerasa, para un volumen final de reacción de $25 \mu \mathrm{l}$. Las condiciones de termociclado fueron; $95^{\circ} \mathrm{C}$ por 10 minutos, seguido de 49 ciclos de $95^{\circ} \mathrm{C}$ por $2 \mathrm{~s}, 60^{\circ} \mathrm{C}$ por $10 \mathrm{~s}, 72^{\circ} \mathrm{C}$ por 15 $\mathrm{s}$, realizadas en un termociclador IQ5 de $\operatorname{Biorad}^{\circledR}(7)$.

El producto de amplificación fue clonado utilizando el vector PCR ${ }^{\circledR}$ 2.1-TOPO de invitrogen ${ }^{\circledR}$. Este se dejó a temperatura ambiente por un periodo de 10-30 minutos para garantizar que el fragmento amplificado se insertara en el vector; transcurrido este tiempo se guardó a $-20^{\circ} \mathrm{C}$. El proceso de transformación se realizó siguiendo el protocolo descrito por $(24,7)$, utilizando células de Escherichia coli DH5 $\alpha$ electrocompetentes y solución salina a una concentración final de $300 \mathrm{mM}(\mathrm{NaCl})$ y $50 \mathrm{mM}(\mathrm{MgCl} 2)$; se utilizó un electroporador (BioRad Gene Pulser ${ }^{\circledR}$ ), programado para un voltaje de $1.8 \mathrm{Kv}$, con un tiempo promedio de electroporación de 5.6 milisegundos. Las células fueron recuperadas en $600 \mu$ de medio de selección 2XYT líquido sin antibiótico, a una temperatura de $37^{\circ} \mathrm{C}$ y en agitación constante durante una hora. Posteriormente, fueron sembradas sobre medio de selección sólido con antibiótico (ampicilina $100 \mathrm{mg}$ / $\mathrm{ml}$ ) e incubadas a $37^{\circ} \mathrm{C}$ durante 16 horas $(24,7)$; a continuación, se llevó a cabo la extracción del DNA plasmídico mediante el protocolo de lisis alcalina propuesto por (38).

\section{Amplificación por PCR en tiempo real}

La pareja de iniciadores: PM197F y PM198R, diseñados previamente en el IVIA por (7), fue utilizada para la amplificación de un fragmento de 186 pares de bases (pb). Se utilizó el fluorocromo Platinum SYBR Green qPCR SuperMix-UDG ${ }^{\circledR}$, de Invitrogen ${ }^{\circledR}$, a una concentración de $1 \mathrm{X}$ y $0,16 \mu \mathrm{M}$ de cada iniciador, para un volumen final de reacción de $25 \mu \mathrm{l}$, siguiendo las instrucciones del fabricante. Las condiciones de termociclado fueron las siguientes: $95^{\circ} \mathrm{C}$ por 10 minutos, seguido de 45 ciclos de $95^{\circ} \mathrm{C}$ por $2 \mathrm{~s}, 60^{\circ} \mathrm{C}$ por $10 \mathrm{~s}, 72^{\circ} \mathrm{C}$ por $15 \mathrm{~s}$, utilizando un termociclador IQ5 de Biorad $^{\circledR}$; se adicionó un ciclo final para la lectura de la curva melting o curva de fusión (7).

\section{E. Curva estándar}

La elaboración de los estándares para la curva de referencia de PCR en tiempo real se realizó a partir de ADN plasmídico, que fue cuantificado en un NanoDrop Spectrophotometer ND-1000 ${ }^{\circledR}$, midiéndose los rangos de absorbancia de; $A_{260} / A_{280}$ y $A_{260} / A_{230}$. El ADN utilizado para este trabajo presentó una concentración inicial de $183 \mathrm{ng} / \mu \mathrm{l}$, que correspondió a $4,08 \times 10^{10}$ copias; el número de copias se determinó siguiendo lo señalado por (27). Para la elaboración de la curva se realizaron tres ensayos, cada uno por triplicado, con el fin de comprobar la reproducibilidad de la técnica. La determinación de sensibilidad fue realizada a partir de una concentración inicial de $1 \times 10^{8}$ copias, preparando diluciones seriadas hasta $1 \times 10^{3}$ copias, que posteriormente fueron almacenadas a $-70{ }^{\circ} \mathrm{C}$.

\section{Resultados}

El método de cuantificación absoluta qRT-PCR permitió detectar el patógeno presente en las muestras 
analizadas; entretanto, la cuantificación absoluta evidenció distintos niveles de acumulación de las partículas virales para los diferentes tejidos vegetales.

\section{A. Amplificación de un fragmento de $A R N$ genómico (ARNg) del virus de la tristeza de los cítricos (CTV)}

Mediante el procedimiento de Transcripción Reversa (RT) y posterior amplificación del ADNc utilizando PCR, se obtuvó un producto final de un tamaño aproximado de 186 pb, visualizado en un gel de agarosa al $2 \%$, como se observa en la Figura 1.

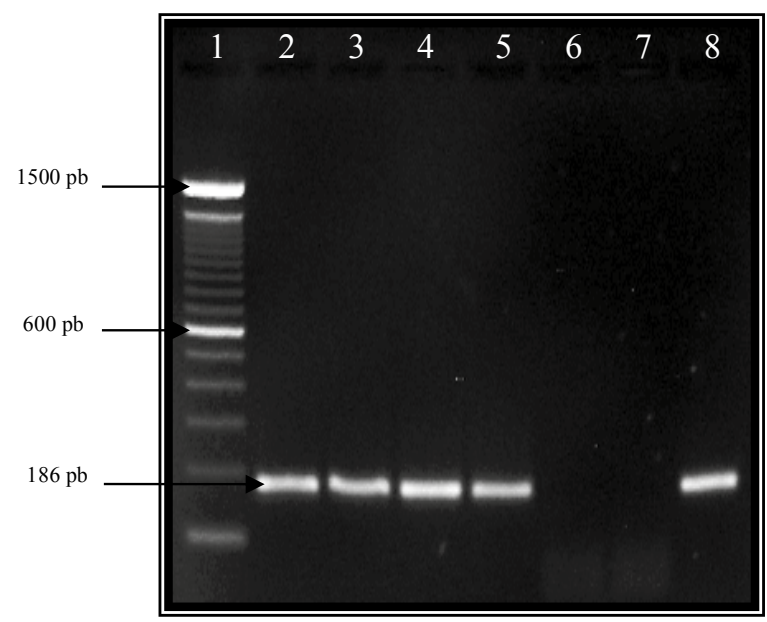

Fig. 1. Detección de CTV por RT-PCR. En la línea 1: marcador de peso molecular $100 \mathrm{pb}$ de Invitrogen. Línea 2-5, muestras: V01f, C01f, Y01, Ica01f. Línea 6-7: blanco y control negativo (ADNc de cítricos sanos), Línea 8: control positivo, (ADNc de cítricos sintomáticos).

\section{B. Optimización de PCR en Tiempo Real}

La pareja de iniciadores PM197F-PM198R detectó ARNg correspondiente al virus CTV para cualquier tejido de cítricos, proporcionando los valores más bajos de ciclo del umbral (Ct). En los análisis mostrados de la curva melting (curva de fusión) para CTV se pudo determinar que el pico de temperatura de fusión tuvo un rango variado entre el intervalo de $81.5^{\circ} \mathrm{C}$ a $83^{\circ} \mathrm{C}$, que correspondió al producto obtenido por estos iniciadores, además de confirmar la ausencia de dímeros de iniciadores o de algún tipo de inespecificidad (Figura 1 y Gráfica 1).

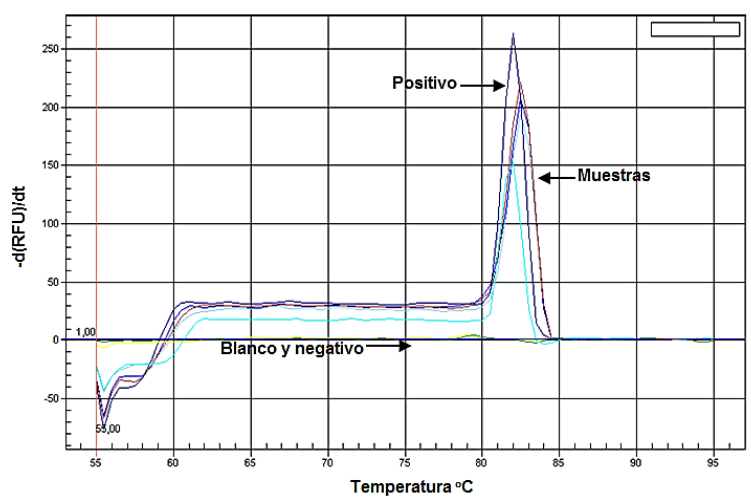

Gráfica 1. Curva de fusión para la amplificación de ARNg de CTV. En el eje (x) se observa la temperatura en grados celsius, y en el eje (y), el rango de unidades de fluorescencia relativa (UFR).

Una vez optimizada la PCR en tiempo real y a partir de los estándares de ADN plasmídico, se obtuvó la curva estándar de referencia para la cuantificación de CTV, resultados mostrados en la Gráfica 2. La curva estandarizada tuvo un coeficiente de correlación de 0,998 y una eficiencia de 99,1\%. 


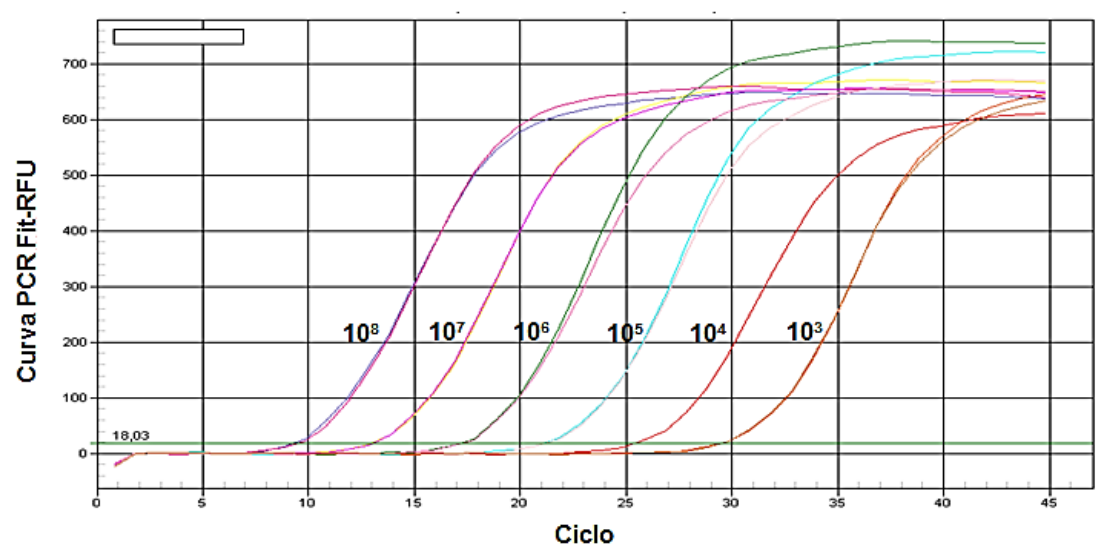

A

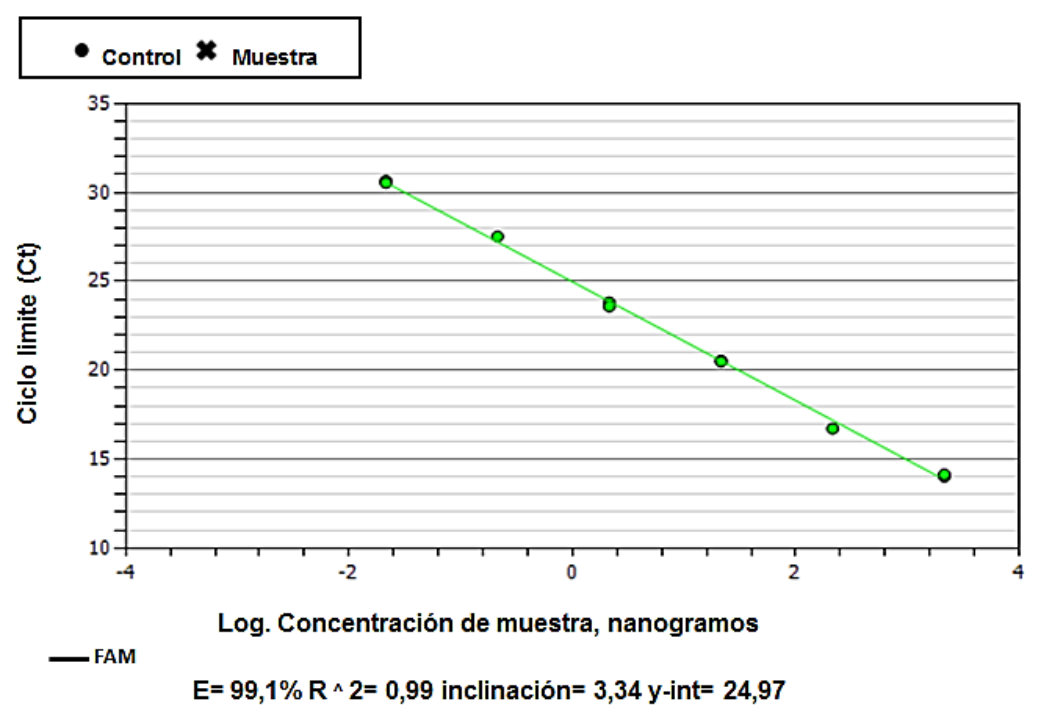

Gráfica 2. Curva estándar de referencia para la cuantificación de CTV. (A) Curvas de amplificación obtenidas a partir de diferentes concentraciones de ADN plasmídico. El número de copias usadas fue en el orden de $1 \times 10^{8}$ a $1 \times 10^{3}$. (B) Curva estándar de referencia obtenida mediante regresión lineal de los valores del ciclo del umbral $(\mathrm{Ct})$ vs. el logaritmo de las concentraciones iniciales conocidas.

\section{Estimación del número de copias de $A R N$ genómico}

La cuantificación se realizó, inicialmente, a nivel de tejido foliar, donde los valores medios del ciclo del umbral $(\mathrm{Ct})$ estaban dentro del rango dinámico de la curva estándar, entre $18,10 \pm 0,111 \mathrm{~mol} / \mathrm{ng}$, a $27,26 \pm 0,106 \mathrm{~mol} / \mathrm{hg}$. Los valores porcentuales del coeficiente de variación $(\mathrm{CV} \%)$ dentro del ensayo se encontraron en un rango de $0,38 \%$ a
1,17 \%, mostrando buena reproducibilidad de la técnica, como se observa en la Tabla II. El número estimado de copias del ARNg para los diversos aislados se extendió desde $8,27 \times 10^{5} \mathrm{~mol} / \mathrm{ng} \pm$ $4,92 \times 10^{4} \mathrm{~mol} / \mathrm{ng}$ a $6,01 \times 10^{3} \mathrm{~mol} / \mathrm{ng} \pm 3,43 \times 10^{2}$ $\mathrm{mol} / \mathrm{ng}$ de ARN total (ARNt), donde las muestras procedentes de Villavicencio (Lima Tahití) y de Tibaitatá mostraron el nivel de acumulación más altos, y las muestras procedentes de Yopal y de Bochalema, el más bajo (Tabla II). 
Tabla II. Detección y cuantificación absoluta de copias de ARN genómico (ARNg) de CTV en las muestras usando una curva estándar externa.

\begin{tabular}{cccc}
\hline Muestra & $\mathbf{C}_{\mathbf{t}} \pm$ D.S. $^{\mathbf{a}}$ & $\mathbf{C v}^{\mathbf{a}^{\mathbf{b}}}$ & Número de copias (x $\mathbf{E}$ E.S.) $^{\mathbf{c}}$ \\
\hline V01 & $20,63 \pm 0,230$ & 1,11 & $2,15 \times 10^{5} \pm 4,48 \times 10^{4}$ \\
V02 & $23,14 \pm 0,130$ & 0,56 & $5,85 \times 10^{4} \pm 2,76 \times 10^{4}$ \\
V03 & $18,10 \pm 0,111$ & 0,61 & $8,27 \times 10^{5} \pm 4,92 \times 10^{4}$ \\
Y01 & $24,73 \pm 0,044$ & 0,17 & $2,38 \times 10^{4} \pm 5,66 \times 10^{3}$ \\
Y02 & $24,63 \pm 0,290$ & 1,17 & $2,50 \times 10^{4} \pm 5,34 \times 10^{3}$ \\
Ica 01 & $19,13 \pm 0,124$ & 0,64 & $4,78 \times 10^{5} \pm 3,18 \times 10^{4}$ \\
Ica 02 & $0,00 \pm N / A^{\mathbf{d}}$ & - & $0,00 \pm 0,00$ \\
C01 & $27,04 \pm 0,200$ & 0,73 & $6,80 \times 10^{3} \pm 7,30 \times 10^{2}$ \\
C02 & $27,26 \pm 0,106$ & 0,38 & $6,01 \times 10^{3} \pm 3,43 \times 10^{2}$ \\
\hline
\end{tabular}

a Promedio del Ciclo umbral (Ct) y desviación estándar (D.S.) obtenida en los ensayos usando tres réplicas.

b coeficiente de variación (CV\%) interensayos.

c Promedio del número de copias $(X)$ por nanogramo de ARN total y error estándar (E.S.).

d No amplifica (N/A).

D. Acumulación de CTV en diferentes partes de plantas cultivadas en campo

Posteriormente, se determinó la carga viral en diferentes hospederos y tejidos de la planta, como lo son la corteza, el fruto y el tejido foliar; en este último se cuantificó a nivel de tercio superior, tercio medio y tercio inferior de la altura de la planta. Los valores del Ct obtenidos para los diferentes hospederos variaron de 23,43 $\pm 0,086 \mathrm{~mol} / \mathrm{ng}$ a $24,65 \pm$ $0,135 \mathrm{~mol} / \mathrm{ng}$, y los valores de $\mathrm{CV} \%$ fueron bajos, entre $0,12 \%$ y $0,54 \%$ para naranjo y limón; Ct de $21,92 \pm 0,044 \mathrm{~mol} / \mathrm{ng}$ a $24,84 \pm 0,041 \mathrm{~mol} / \mathrm{ng}$ y valores de CV\% entre $0,05 \%$ y $1,41 \%$ para los injertos. El número estimado de copias del ARNg se dio entre $2,13 \times 10^{4} \pm 1,56 \times 10^{3} \mathrm{~mol} / \mathrm{ng}$ y $4,11 \times 10^{4}$ $\pm 1,92 \times 10^{3} \mathrm{~mol} / \mathrm{ng}$ ARNt para la naranja dulce $\mathrm{y}$ limón, y entre $1,94 \times 10^{4} \pm 4,28 \times 10^{3}$ y $9,29 \times 10^{4} \pm$ $2,22 \times 10^{3} \mathrm{~mol} / \mathrm{ng}$ ARNt para los injertos, como lo muestran las Tablas III y IV. Presentándose la mayor concentración de carga viral a nivel de tejido foliar, seguido de fruto y, por último, la corteza.

Tabla III. Detección y cuantificación absoluta de copias de ARN genómico (ARNg) de CTV en diferentes tejidos de naranjo y limón mandarino usando una curva estándar externa.

\begin{tabular}{lccccc}
\hline Muestra & Cítrico & Tejido & C $_{\mathbf{t}} \pm$ D.S. $^{\mathbf{a}}$ & $\mathbf{C v}^{\mathbf{b}}$ & Número de copias $\left(\mathbf{x} \pm\right.$ E.S.) $^{\mathbf{c}}$ \\
\hline \multirow{3}{*}{ Ica 01 } & \multirow{3}{*}{ Naranjo dulce } & Foliolo & $23,43 \pm 0,086$ & 0,36 & $4,11 \times 10^{4} \pm 1,92 \times 10^{3}$ \\
& & Corteza & $24,65 \pm 0,135$ & 0,54 & $2,13 \times 10^{4} \pm 1,56 \times 10^{3}$ \\
& & Fruto & $23,88 \pm 0,030$ & 0,12 & $3,22 \times 10^{4} \pm 5,18 \times 10^{2}$ \\
\hline \multirow{4}{*}{ Ica 02 } & \multirow{3}{*}{ Limón mandarino } & Foliolo & $0,00 \pm 0,00$ & - & $0,00 \pm 0,00$ \\
& & Corteza & $0,00 \pm 0,00$ & -- & $0,00 \pm 0,00$ \\
& & Fruto & $0,00 \pm 0,00$ & -- & $0,00 \pm 0,00$ \\
\hline
\end{tabular}

a Promedio del Ciclo umbral (Ct) y desviación estándar (D.S.) obtenida en el ensayos usando tres réplicas. b coeficiente de variación $(\mathrm{CV} \%)$ interensayos.

c Promedio del número de copias $(X)$ por nanogramo de ARN total y error estándar (E.S.). 
Tabla IV. Detección y cuantificación absoluta de copias de ARN genómico (ARNg) de CTV en diferentes tejidos de injertos usando una curva estándar externa.

\begin{tabular}{cccccc}
\hline \multirow{2}{*}{ Muestra } & Patrón/injerto & Tejido & $\boldsymbol{C}_{\mathbf{t} \pm \text { D.S. }}{ }^{\mathbf{a}}$ & $\mathbf{C v}^{\mathbf{b}}$ & Número de copias $\left(\boldsymbol{x} \pm\right.$ E.S.) $^{\mathbf{c}}$ \\
\hline \multirow{2}{*}{ V01 } & Cleopatra/L. Tahití & Foliolo & $22,65 \pm 0,157$ & 0,69 & $6,50 \times 10^{4} \pm 2,45 \times 10^{3}$ \\
& Cleopatra/L. Tahití & Corteza & $24,71 \pm 0,350$ & 1,41 & $2,10 \times 10^{4} \pm 5,93 \times 10^{3}$ \\
& Cleopatra/L. Tahití & Fruto & $24,31 \pm 0,210$ & 0,86 & $3,52 \times 10^{4} \pm 3,43 \times 10^{3}$ \\
\hline \multirow{2}{*}{ V03 } & Sunky/L. Tahití & Foliolo & $21,92 \pm 0,044$ & 0,20 & $9,29 \times 10^{4} \pm 2,22 \times 10^{3}$ \\
& Sunky/L. Tahití & Corteza & $24,84 \pm 0,041$ & 0,16 & $1,94 \times 10^{4} \pm 4,28 \times 10^{3}$ \\
& Sunky/L. Tahití & Fruto & $23,10 \pm 0,013$ & 0,05 & $4,91 \times 10^{4} \pm 3,37 \times 10^{2}$ \\
\hline
\end{tabular}

a Promedio del Ciclo umbral (Ct) y desviación estándar (D.S.) obtenida en el ensayos usando tres réplicas.

b Coeficiente de variación (CV\%) interensayos.

c Promedio del número de copias (X) por nanogramo de ARN total y error estándar (E.S.).

Debido a que la mayor carga viral se presentó en el tejido foliar, se llevó a cabo una detección y cuantificación de tejido foliar a nivel de tercio superior, tercio medio y tercio inferior, para ver la disposición del virus en la planta. Los valores del Ct obtenidos para las diferentes muestras de tejido foliar variaron de $17,23 \pm 0,079 \mathrm{~mol} / \mathrm{ng}$ a 22,56 $\pm 0,046 \mathrm{~mol} / \mathrm{ng}$, y los valores de CV\% fueron ba- jos, entre $0,05 \%$ y $0,45 \%$. El número estimado de copias del ARNg se encontró entre $4,82 \times 10^{4}$ $\pm 1,13 \times 10^{3} \mathrm{~mol} / \mathrm{ng}$ y $7,39 \times 10^{5} \pm 3,01 \times 10^{4} \mathrm{~mol} /$ ng ARNt; donde la más alta concentración se dio en el tercio superior, seguido del tercio inferior $y$, por último, el tercio medio, como se observa en la Tabla V.

Tabla V. Detección y cuantificación absoluta de copias de ARN genómico de CTV en los diferentes tercios del tejido foliar de la planta usando una curva estándar externa.

\begin{tabular}{|c|c|c|c|c|c|}
\hline Muestra & Cítrico & $\begin{array}{c}\text { Tercio de la } \\
\text { planta }\end{array}$ & $C_{t} \pm$ D.S..$^{a}$ & $\mathrm{Cv} \%{ }^{\mathrm{b}}$ & $\begin{array}{l}\text { Número de copias } \\
\qquad(x \pm E . S .)^{c}\end{array}$ \\
\hline \multirow{3}{*}{ V01f } & \multirow[b]{3}{*}{$\begin{array}{c}\text { Limón Tahití en } \\
\text { Cleopatra }\end{array}$} & T. Superior & $17,23 \pm 0,079$ & 0,45 & $7,39 \times 10^{5} \pm 3,01 \times 10^{4}$ \\
\hline & & T. Medio & $20,01 \pm 0,043$ & 0,21 & $1,80 \times 10^{5} \pm 3,95 \times 10^{4}$ \\
\hline & & T. Inferior & $18,44 \pm 0,071$ & 0,38 & $4,11 \times 10^{5} \pm 1,48 \times 10^{4}$ \\
\hline \multirow{3}{*}{ V03f } & Limón Tahití en & T. Superior & $18,74 \pm 0,068$ & 0,36 & $3,50 \times 10^{5} \pm 1,20 \times 10^{4}$ \\
\hline & Sunky por Jacob- & T. Medio & $19,90 \pm 0,010$ & 0,05 & $1,88 \times 10^{5} \pm 1,24 \times 10^{2}$ \\
\hline & son & T. Inferior & $19,33 \pm 0,063$ & 0,32 & $2,59 \times 10^{5} \pm 8,30 \times 10^{4}$ \\
\hline \multirow{3}{*}{ Ica $01 \mathrm{f}$} & \multirow[b]{3}{*}{ Naranjo } & T. Superior & $19,35 \pm 0,055$ & 0,28 & $2,54 \times 10^{5} \pm 7,06 \times 10^{4}$ \\
\hline & & T. Medio & $22,56 \pm 0,046$ & 0,20 & $4,82 \times 10^{4} \pm 1,13 \times 10^{3}$ \\
\hline & & T. Inferior & $20,03 \pm 0,059$ & 0,29 & $1,76 \times 10^{5} \pm 5,35 \times 10^{3}$ \\
\hline
\end{tabular}

a Promedio del Ciclo umbral (Ct) y desviación estándar (D.S.) obtenido en los ensayos usando tres réplicas. b coeficiente de variación (CV\%) interensayos.

c Promedio del número de copias $(X)$ por nanogramo de ARN total y error estándar (E.S.). 


\section{Discusión y conclusiones}

El diagnóstico de CTV, agente causal de una de las enfermedades más onerosas en el cultivo de los cítricos (4), fue realizado por indexación biológica, serología, hibridación molecular o técnica de PCR (28-34, 13, 23), pero ninguno de estos procedimientos permite la cuantificación exacta de la acumulación del virus (7). La PCR en tiempo real ha sido adaptada como método diagnóstico debido a su mejor celeridad y reproducibilidad, además de reducir el riesgo de contaminación (20). En el presente trabajo se aplicó un protocolo cuantitativo de PCR en tiempo real que estima de manera confiable el número de copias de RNA genómico (ARNg) de CTV en el ARN total (ARNt) extraído del tejido de cítricos infectados.

En comparación con los programas basados en sondas de secuencia específicas, el uso de SYBR Green elimina el costo de la síntesis de la sonda, permite la valoración exacta de la carga viral sobre un amplio rango y es un procedimiento confiable para la cuantificación de CTV, puesto que la detección no es afectada por secuencias heterogéneas en la región abarcada por los iniciadores (35).

Este protocolo permitió la valoración exacta del número de copias del ARNg en los diferentes tejidos de las diversas especies de cítricos infectados con el virus CTV, los cuales se diferencian por la característica de su patogenicidad $(7,15)$. Fue notorio en los análisis realizados que la acumulación de ARNg de CTV varió con el tipo de tejido y con la especie del hospedero donde se cuantificó, mostrando que hay mayor tendencia de acumulación del virus en el tejido foliar que en la corteza o el fruto.

Los estudios anteriores, basados en la detección de la cubierta proteica de CTV mediante ELISA, no encontraron diferencias claras en la carga viral de los tejidos de brotes, hojas o pedúnculos del fruto (28); sin embargo, los datos obtenidos en el presente trabajo sugieren que el número de copias de ARNg en los diferentes cultivos de cítricos fue mayor en las variedades injertadas (Limón Tahití, Citrus latifolia, en Cleopatra, Limón Tahití en Sunky $x$ Jacobson) que en las de naranjo dulce ( $\mathrm{Ci}-$ trus sinensis) o limón mandarino (Híbrido: Citrus $x$ limonia).

El radio de dispersión de los virus de célula a célula varía de acuerdo con la clase y edad de las células de las plantas infectadas, y es mayor en células alargadas y jóvenes que en las viejas y redondas (4), lo cual se vio reflejado en el análisis que se realizó a nivel de tejido foliar y en los diferentes tercios de la planta, donde la mayor concentración se presentó en el tercio superior de la planta, y la menor, en el tercio medio.

En (36) se utilizó la técnica de Polimorfismos en la Longitud de los Fragmentos de Restricción (RFLP) con las enzimas de restricción Hae III y Kpn I para diferenciar las razas débiles de las severas; sin embargo, la sensibilidad de la RT-PCR en tiempo real fue 1000 veces superior a la RT-PCR convencional y a la inmuno-captura (IC)-RT-PCR, y $1 \times 10^{6}$ veces mayor que las técnicas de inmunodetección ligadas a enzimas (ELISA) $(11,37)$. Lo anterior es importante para futuros estudios de discriminación de aislamientos de CTV utilizando la técnica de RT-PCR en tiempo real, como se realizó en (3), donde se identificó mediante esta técnica y el uso de sondas taqMan la presencia de aislamientos inductores de características graves y moderadas y de los aislamientos T-36. En (37) se desarrolló una multiplex RT-qPCR para la detección simultánea de Citrus psorosis virus (CPsV), Citrus variegation virus (CVV) y Citrus tristeza virus (CTV), en una sola reacción, la cual demostró ser 1000 veces más sensible que las técnicas convencionales de detección, proporcionando así una valiosa herramienta como alternativa para la detección de estos virus y otros agentes fitopatógenos de cítricos.

Estos resultados indican que el procedimiento aquí descrito es de utilidad no solo para los diagnósticos, sino también para estudiar diversos aspectos de la biología del virus, como la respuesta de los diferentes órganos a la infección por este, los efectos potenciales de la acumulación del virus en brotes jóvenes, la expresión de síntomas y la transmisibilidad del áfido, además de la resistencia relativa de diversos cultivares o plantas transgénicas de cítricos a aislamientos específicos de CTV (7). 
De igual manera, la detección rápida y precisa de CTV obtenida en este trabajo mediante el uso de qRT-PCR representa una herramienta de apoyo a las medidas de control para limitar la propagación de la enfermedad; además, puede implementarse en los programas de cuarentena, erradicación y certificación $(10,23)$, debido a la importancia económica de los cítricos y a su susceptibilidad hacia ciertos artrópodos y patógenos transmisibles por medio de injertos. La técnica de PCR en tiempo real es un método específico y sensible, de utilidad en los procesos de detección de las enfermedades virales presentes en este y otros cultivos de interés agrícola.

\section{Agradecimientos}

Los autores expresan sus agradecimientos al Instituto Colombiano Agropecuario -ICA- por el apoyo y financiamiento de la presente investigación, y al equipo de trabajo del Departamento de Biología Molecular, adscrito al Laboratorio Nacional de Diagnóstico Fitosanitario-ICA-Tibaitatá-Cundinamarca.

\section{Referencias}

(1) Caicedo A., Muñoz O., Triviño A., Gómez JE. Bases para la certificación de plántulas de cítricos libres de enfermedades en Colombia. Novedades Técnicas. 2006; 7: 9-16.

(2) Morales J., Acosta O., Tamayo P., Peñaranda J. Characterization of Citrus tristeza virus isolates from Colombia. Rev. Protección Veg. 2013; 28(1): 45-53.

(3) Ruiz-Ruiz S., Moreno P., Guerri J., Ambros S. Discrimination between mild and severe Citrus tristeza virus isolates with a rapid and highly specific Real-Time Reverse Transcription-polymerase chain reaction method using TaqMan LNA probe. Phytopathology. 2009; 99: 307-315. DOI: http://doi.org/10.1094/ PHYTO-99-3-0307.

(4) Dawson WO., Bar-Joseph M., Garnsey SM., Moreno P. Citrus tristeza virus: Making an Ally from an Enemy. Annu. Rev. Phytopathol. 2015; 53: 137-55. DOI: http://doi.org/10.1146/annurev-phyto-080614-120012.

(5) Oliveros GO., Martínez SN., Torres R., Acosta O. CPm gene diversity in field isolates of Citrus tristeza virus from Colombia. Archives of Virology. 2009; 154(12): 1933-1937. DOI: http://doi. org/10.1007/s00705-009-0530-6.

(6) Costa A., Nunes W., Zanutto C., Müller G. Stability of Citrus tristeza virus protective isolates in field conditions. Pesquisa Agropecuaria Bras. 2010; 45(7): 693-700. DOI: http://doi. org/10.1590/S0100-204X2010000700009.
(7) Ruiz-Ruiz S., Moreno P., Guerri J., Ambros S. A Real-Time RT-PCR assay for detection and absolute quantitation of Citrus tristeza virus in different plant tissues. Journal of virogical methods. 2007; 145: 96-105. DOI: http://doi.org/10.1016/j.jviromet.2007.05.011.

(8) Harper SJ. Citrus tristeza virus: evolution of complex and varied genotypic groups. Front. Microbiol. 2013; 4: 93. DOI: http://doi. org/10.3389/fmicb.2013.00093.

(9) Febres VJ., Ashoulin L., Mawassi M., Frank A., Bar-Joseph M., Manjunath KL., Lee RF., Niblett CL. The p27 protein is present at one end of Citrus tristeza virus particles. Phytopathology. 1996; 86: 1331-1335.

(10) Saponari M., Manjunath K., Yokomi R. Quantitative detection of Citrus tristeza virus in citrus and aphids by Real-Time reverse transcription-PCR (TaqMan). Journal of Virogical Methods. 2008; 147: 43-53. DOI: http://doi.org/10.1016/j.jviromet.2007.07.026.

(11) Bertolini E., Moreno A., Capote N., Olmos A., Vidal E., Pérez J., Cambra M. Quantitative detection of Citrus tristeza virus in plant tissues and single aphid by Real-Time RT-PCR. Plant Pathology. 2008; 120: 177-188. DOI: http://doi.org/10.1007/s10658-0079206-9.

(12) Gómez G. Estado actual de la citricultura en cifras, pp. 12-20. En: Gómez B. G, Caicedo A. A, Gil V. L, (eds.). Tecnología para el cultivo de cítricos en la región Caribe colombiana, Produmedios, Colombia, 2008.

(13) Rodríguez P., Romero de Pérez G., Guzmán M. Detección del virus de la tristeza de los cítricos por serología, microscopía e hibridación in situ. Revista Colombiana de Biotecnología. 2009; XI(1): 94-106.

(14) Satyanarayana T., Bar-Joseph M., Mawassi M., Albiach-Martí MR., Ayllón MA., Gowda S., Hilf ME., Moreno P., Garnsey SM., Dawson WO. Amplification of Citrus tristeza virus from a cDNA clone and infection of citrus trees. Virology. 2001; 280: 87-96. DOI: http://doi.org/10.1006/viro.2000.0759.

(15) Ananthakrishnan G., Venkataprasanna T., Roy A., Brlansky R. Characterization of the mixture of genotypes of a Citrus tristeza virus isolate by reverse transcription-quantitative real-time PCR. Journal of Virological Methods. 2010; 64(1-2): 75-82. DOI: http://doi.org/10.1016/j.jviromet.2009.12.001.

(16) Folimonova SY., Robertson CJ., Shilts T., Folimonov AS., Hilf ME. Infection with strains of Citrus tristeza virus does not exclude superinfection by other strains of the virus. J. Virol. 2010; 84: 1314-25. DOI: http://doi.org/10.1128/JVI.02075-09.

(17) Heid CA., Stevens J., Livak KJ., Williams PM. Real time quantitative PCR. Genome Res. 1996; 6: 986-994. DOI: http://doi. org/10.1101/gr.6.10.986.

(18) Freeman WM., Walker SJ., Vrana KE. Quantitative RT-PCR: pitfalls and potential. Biotechniques. 1999; 26: 112-125.

(19) Bustin SA. Quantification or mRNA using real-time reverse transcription PCR (RT-PCR): trends and problems. J. Mol. Endocrinol. 2002; 29: 23-29. DOI: http://doi.org/10.1677/jme.0.0290023.

(20) Mackay IM., Arden KE., Nitsche A. Real time PCR in virology. Nucleic Acids Res. 2002; 30: 1292-1305. DOI: http://doi. org/10.1093/nar/30.6.1292. 
(21) Whelan JA., Rusell NB., Whelan MA. A method for the absolute quantification of cDNA using real-time PCR. Journal of Immunological Methods. 2003; 278: 261-269. DOI: http://doi. org/10.1016/S0022-1759(03)00223-0.

(22) Tan BH., Lim EA., Liaw JC., Seah SG., Yap EP. Diagnostic value of real-time capillary thermal cycler in virus detection. Expert Rev. Mol. Diagn. 2004; 4: 219-230. DOI: http://doi. org/10.1586/14737159.4.2.219.

(23) Roy A., Ananthakrishnan G., Hartung JS., Brlansky RH. Development Citrus tristeza virus and application of a multiplex reverse transcription polymerase chain reaction assay for screening a global collection of Citrus tristeza virus isolates. Phytopathology. 2010; 100: 1077-1088. DOI: http://doi.org/10.1094/ PHYTO-04-10-0102.

(24) Mirmajlessi S., Loit E. General principles of real-time PCR: a technology for quantitative detection of phytopathogens. Journal of medical and bioengineering. 2016; 5(1), February.

(25) Rutledge RG., Coté C. Mathematics of quantitative kinetic PCR and the application of standard curves. Nucleic Acids Research. 2003; 31: 93. DOI: http://doi.org/10.1093/nar/gng093.

(26) Casal J., Mateu E. Tipos de muestreo. Rev. Epidem. Med. Prev. 2003; 1: 3-7.

(27) Lee C., Kim J., Shin SG., Hwang S. Absolute and relative qPCR quantification of plasmid copy number in Escherichia coli. Journal of Biotechnology. 2006; 123: 273-280. DOI: http://doi.org/10.1016/j.jbiotec.2005.11.014.

(28) Cambra M., Gorris MT., Olmos A., Martínez MC., Roman MP., Bertolini E., López A., Carbonell EA. European diagnostic protocols (DIAG-PRO) for Citrus Tristeza Virus in adult trees. In: Duran-villa N, Milne R. G., Da Graca J. V., (Eds.). En: Procedings of the 15th conference of the International Organization of citrus virologists. IOCV, Riverside, CA, 2002.

(29) Narváez G., Skander BS., Ayllon MA., Rubio L., Guerri J., Moreno $P$. A new procedure to differentiate Citrus tristeza virus isolates by hybridisation with digoxigenin-labelled cDNA probes. J. Virol. Methods. 2000; 85: 83-92. DOI: http://doi.org/10.1016/ S0166-0934(99)00158-5.

(30) Nolasco G., de Blas C., Torres V., Ponz F. A method combining immunocapture and PCR amplification in a microtiter plate for the detection of plant viruses and subviral pathogens. J. Virol. Methods. 1993; 45: 201-218. DOI: http://doi.org/10.1016/0166-0934(93)90104-Y.

(31) Olmos A., Cambra M., Esteban O., Gorris MT., Terrada E. New device and method for capture, reverse transcription and nested PCR in a single closed-tube. Nucleic Acids Res. 1999; 27: 15641565. DOI: http://doi.org/10.1093/nar/27.6.1564.

(32) Permar TA., Garnsey SM., Gumpf DJ., Lee RF. A monoclonal antibody which discriminates strains of Citrus tristeza virus. Phytopathology. 1990; 80: 224-228. DOI: http://doi.org/10.1094/ Phyto-80-224.

(33) Roistacher CN. Graft-transmissible diseases of citrus. En: Handbook for Detection and Diagnosis. FAO, Rome, Italy, 1991

(34) Vela C., Cambra M., Cortés E., Moreno P., Miguet JG., Pérez de San Román C., Sanz A. Production and characterization of monoclonal antibodies specific for Citrus tristeza virus and their use for diagnosis. J. Gen. Virol. 1986; 67: 91-96. DOI: http://doi. org/10.1099/0022-1317-67-1-91.

(35) Papin JF., Vahrson W., Dittmer DP. SYBR green-based real-time quantitative PCR assay for detection of West Nile virus circumvents false-negative results due to strain variability. J. Clin. Microbiol. 2004; 42: 1511-1518. DOI: http://doi.org/10.1128/ JCM.42.4.1511-1518.2004.

(36) Mendoza A., Salazar A., Alvarado O., Cruz MA., Barrera HA. Caracterización molecular de razas severas y débiles del virus de la tristeza de los cítricos. Ciencias UANL. 2005; 8: 250-258.

(37) Loconsole G., Saponari M., Savino V. Development of Real-Time PCR based assays for simultaneous and improved detection of citrus virus. Plant Pathology. 2010; 128: 251-259. DOI: http:// doi.org/10.1007/s10658-010-9653-6.

(38) Sambrook J, Fritschi EF., Maniatis T. Molecular cloning: a laboratory manual, Cold Spring Harbor Laboratory Press, New York, 1989. 